\title{
Experimental Investigation on Physical, Thermal and Spectroscopic Properties of 2-Chlorobenzonitrile: Impact of Biofield Treatment
}

\author{
Mahendra Kumar Trivedi ${ }^{1}$, Alice Branton ${ }^{1}$, Dahryn Trivedi ${ }^{1}$, Gopal Nayak ${ }^{1}$, Ragini Singh ${ }^{2}$, \\ Snehasis Jana ${ }^{2, *}$ \\ ${ }^{1}$ Trivedi Global Inc., Henderson, USA \\ ${ }^{2}$ Trivedi Science Research Laboratory Pvt. Ltd., Bhopal, Madhya Pradesh, India
}

Email address:

publication@trivedisrl.com (S. Jana)

\section{To cite this article:}

Mahendra Kumar Trivedi, Alice Branton, Dahryn Trivedi, Gopal Nayak, Ragini Singh, Snehasis Jana. Experimental Investigation on Physical, Thermal and Spectroscopic Properties of 2-Chlorobenzonitrile: Impact of Biofield Treatment. Modern Chemistry.

Vol. 3, No. 4, 2015, pp. 38-46. doi: 10.11648/j.mc.20150304.11

\begin{abstract}
ClBN) is widely used in the manufacturing of azo dyes, pharmaceuticals, and as intermediate in various chemical reactions. The aim of present study was to evaluate the impact of biofield treatment on physical, thermal and spectroscopic properties of 2-ClBN. 2-ClBN sample was divided into two groups that served as treated and control. The treated group received Mr. Trivedi's biofield treatment. Subsequently, the control and treated samples were evaluated using $\mathrm{X}$-ray diffraction (XRD), surface area analyser, differential scanning calorimetry (DSC), thermogravimetric analysis (TGA), Fourier transform infrared (FT-IR) and ultraviolet-visible (UV-Vis) spectroscopy. XRD result showed a decrease in crystallite size in treated samples i.e. $4.88 \%$ in 2-ClBN along with the increase in peak intensity as compared to control. However, surface area analysis showed a decrease in surface area of $64.53 \%$ in treated 2-ClBN sample as compared to the control. Furthermore, DSC analysis results showed a significant increase in the latent heat of fusion $(28.74 \%)$ and a slight increase in melting temperature (2.05\%) in treated sample as compared to the control. Moreover, TGA/DTG studies showed that the control and treated 2-ClBN samples lost $61.05 \%$ and $46.15 \%$ of their weight, respectively. The FT-IR spectra did not show any significant change in treated 2-ClBN sample as compared to control. However, UV-Vis spectra showed an increase in the intensity of peak as compared to control sample. These findings suggest that biofield treatment has significantly altered the physical, thermal and spectroscopic properties of 2-ClBN, which could make them more useful as a chemical intermediate.
\end{abstract}

Keywords: Biofield Treatment, 2-Chlorobenzonitrile, X-ray Diffraction, Surface Area Analysis,

Differential Scanning Calorimetry, Thermogravimetric Analysis, Fourier Transform Infrared Spectroscopy,

Ultraviolet-Visible Spectroscopy

\section{Introduction}

Benzonitrile is a colourless aromatic organic compound, had a sweet almond odour and derived from the reaction of benzoic acid with lead thiocyanate by heating [1]. They are widely used as an indispensable part in the production of dyes, rubber chemicals, pharmaceuticals, herbicides and natural products. They are present as important substructures in various biologically active agents like bicalutamide, fluvoxamine, fadrozole, etc. [2]. Benzonitriles and its derivatives are also used in manufacturing lacquers, polymers and anhydrous metallic salts [3]. Halogenated benzonitriles are known to be used as intermediate in the synthesis of inhibitors of enzymes related to Chagas, Alzheimer and Parkinson disease [4-6] as well as inhibitors used in HIV and cancer treatment $[7,8]$. 2-Chlorobenzonitrile (2-ClBN) is a halogenated benzonitrile derivative that is mainly used as an intermediate in the production of azo dyes by synthesizing dye intermediates like 2-cyano-4-nitroaniline. It is also used in palladium catalysed direct arylation of heteroaromatics, e.g., 3-aminopicolinic acid and synthesis of antimalarial drug quetiapine nitrate [9]. 2-ClBN and its substituted derivatives e.g. 2,3-dichloro-6-nitrobenzonitrile also have potential anti-inflammatory properties [10]. Stability profile of any chemical compound is the most desired quality that 
determines its shelf life and purity to be used as intermediate. The stability can be correlated to physical, thermal or structural and bonding properties of compound [11]. Currently, the stability of chemical compounds in pharmaceutical industries can be affected due to altering temperature and $\mathrm{pH}$ conditions [12]. Thus, it is important to search some alternate strategies, which could improve the stability of chemical compounds by altering their physical, thermal or structural and bonding properties.

It is already demonstrated that electrical current exists inside the human body in the form of vibratory energy particles like ions, protons, and electrons, and they generate a magnetic field in the human body $[13,14]$. This electromagnetic field of the human body is known as biofield and energy associated with this field is known as biofield energy $[15,16]$. It generates through internal physiological processes like blood flow, brain activity and heart function, and function for regulation and communication within the organism [17]. Currently, many biofield treatments are in practice for their possible therapeutic potentials such as enhanced personal well-being and improved functional quality of life [18-20]. The living organisms are also able to exchange this energy from the environment for their health maintenance. Thus, a human can harness the energy from the environment or universe and can transmit the energy to any living or non-living object around this Universe. The object(s) always receive the energy and respond to useful way via biofield energy. This process is termed as biofield treatment. Mr. Trivedi's biofield treatment (The Trivedi Effect ${ }^{\circledR}$ ) is well known and significantly studied in different fields such as microbiology [21-23], agriculture [24-26], and biotechnology $[27,28]$. Recently, it was reported that biofield treatment changes the atomic, crystalline and powder characteristics as well as spectroscopic characters of different materials. Along with that, alteration in physical, thermal and chemical properties was also reported in materials like antimony, bismuth and ceramic oxide [29-31]. Hence, based on the results obtained after biofield treatment on different materials and considering the pharmaceutical applications of 2-ClBN, the present study was undertaken to evaluate the impact of biofield treatment on physical, thermal and spectroscopic characteristics of 2-ClBN.

\section{Materials and Methods}

2-Chlorobenzonitrile (2-ClBN) was procured from S D Fine Chemicals Pvt. Ltd., India. The sample was divided into two parts; one was kept as a control while other was subjected to Mr. Trivedi's biofield treatment and coded as treated sample. The treatment sample in sealed pack was handed over to $\mathrm{Mr}$. Trivedi for biofield treatment under standard laboratory conditions. Mr. Trivedi provided the treatment through his energy transmission process to the treated group without touching the sample. The biofield treated sample was returned in the similarly sealed condition for further characterization using XRD, surface area analyser, DSC, TGA, FT-IR and $\mathrm{UV}-\mathrm{Vis}$ spectroscopic techniques.

\subsection{X-ray Diffraction (XRD) Study}

XRD analysis was carried out on Phillips, Holland PW 1710 X-ray diffractometer system, which had a copper anode with nickel filter. The radiation of wavelength used by the XRD system was $1.54056 \AA$. The data obtained were in the form of a chart of $2 \theta v s$. intensity and a detailed table containing peak intensity counts, $d$ value $(\AA)$, peak width $\left(\theta^{\circ}\right)$, relative intensity $(\%)$, etc.

The crystallite size $(G)$ was calculated by using formula:

$$
\mathrm{G}=\mathrm{k} \lambda /(\mathrm{b} \operatorname{Cos} \theta)
$$

Here, $\lambda$ is the wavelength of radiation used; $b$ is full width half maximum (FWHM) of peaks and $\mathrm{k}$ is the equipment constant $(=0.94)$. However, percent change in crystallite size was calculated using the following equation:

Percent change in crystallite size $=\left[\left(\mathrm{G}_{\mathrm{t}}-\mathrm{G}_{\mathrm{c}}\right) / \mathrm{G}_{\mathrm{c}}\right] \times 100$

Where, $\mathrm{G}_{\mathrm{c}}$ and $\mathrm{G}_{\mathrm{t}}$ are crystallite size of control and treated powder samples, respectively.

\subsection{Surface Area Analysis}

The surface area was measured by the Surface area analyser, Smart SORB 90 based on Brunauer-Emmett-Teller (BET). Percent changes in surface area were calculated using following equation:

$$
\% \text { change in surface area }=\frac{\left[\mathrm{S}_{\text {Treated }}-\mathrm{S}_{\text {Control }}\right]}{\mathrm{S}_{\text {Control }}} \times 100
$$

Where, $\mathrm{S}_{\text {Control }}$ and $\mathrm{S}_{\text {Treated }}$ are the surface area of control and treated samples, respectively.

\subsection{Differential Scanning Calorimetry (DSC) Study}

For studies related to melting temperature and latent heat of fusion of 2-ClBN, Differential Scanning Calorimeter (DSC) of Perkin Elmer/Pyris-1, USA with a heating rate of $10^{\circ} \mathrm{C} / \mathrm{min}$ under air atmosphere and flow rate of $5 \mathrm{ml} / \mathrm{min}$ was used. Melting temperature and latent heat of fusion were obtained from the DSC curve.

Percent change in latent heat of fusion was calculated using following equations:

$$
\begin{aligned}
& \text { \% change in Latent heat of fusion } \\
& =\frac{\left[\Delta \mathrm{H}_{\text {Treated }}-\Delta \mathrm{H}_{\text {Control }}\right]}{\Delta \mathrm{H}_{\text {Control }}} \times 100
\end{aligned}
$$

Where, $\Delta \mathrm{H}_{\text {Control }}$ and $\Delta \mathrm{H}_{\text {Treated }}$ are the latent heat of fusion of control and treated samples, respectively. Similarly, percent change in melting point was also calculated to observe the difference in thermal properties of treated 2-ClBN sample as compared to control.

\subsection{Thermogravimetric Analysis/Derivative Thermogravimetry (TGA/DTG)}

Thermal stability of control and treated sample of 2-ClBN 
was analysed by using Mettler Toledo simultaneous thermogravimetric analyser (TGA/DTG). The samples were heated from room temperature to $400^{\circ} \mathrm{C}$ with a heating rate of $5^{\circ} \mathrm{C} / \mathrm{min}$ under air atmosphere. From TGA curve, onset temperature $\mathrm{T}_{\text {onset }}$ (temperature at which sample start losing weight) and from DTG curve, $\mathrm{T}_{\max }$ (temperature at which sample lost its maximum weight) were recorded.

Percent change in temperature at which maximum weight loss occur in sample was calculated using following equation:

$\%$ change in $\mathrm{T}_{\max }=\left[\left(\mathrm{T}_{\text {max }}\right.\right.$, treated $\left.\left.-\mathrm{T}_{\max , \text { control }}\right) / \mathrm{T}_{\max , \text { control }}\right] \times 100$

Where, $\mathrm{T}_{\max }$, control and $\mathrm{T}_{\max }$, treated are the temperature at which maximum weight loss occurs in control and treated sample, respectively.

Percent change in onset peak temperature was calculated using following equation:

$\%$ change in onset peak temperature $\mathrm{T}_{\text {onset }}=\left[\left(\mathrm{T}_{\text {onset, treated }}-\mathrm{T}_{\text {onset, }}\right.\right.$ control $\left.) / T_{\text {onset, control }}\right] \times 100$

Where, $\mathrm{T}_{\text {onset, }}$ control and $\mathrm{T}_{\text {onset, treated are onset peak }}$ temperature in control and treated sample, respectively.

\subsection{Spectroscopic Studies}

For determination of spectroscopic characters, the treated sample was divided into two groups i.e. T1 and T2. Both treated groups were analysed for their spectral characteristics using FT-IR and UV-Vis spectroscopy as compared to control 2-ClBN sample.

\subsubsection{FT-IR Spectroscopic Characterization}

The samples were crushed into fine powder for analysis. The powdered sample was mixed in spectroscopic grade $\mathrm{KBr}$ in an agate mortar and pressed into pellets with a hydraulic press. FT-IR spectra were recorded on Shimadzu's Fourier transform infrared spectrometer (Japan) with a frequency range of $4000-500 \mathrm{~cm}^{-1}$. The samples are prepared by grinding the dry blended powders of control and treated 2-ClBN with powdered $\mathrm{KBr}$, and then compressed to form discs. The FT-IR spectroscopic analysis of 2-ClBN (control, T1 and T2) were carried out to evaluate the impact of biofield treatment at atomic and molecular level like bond strength, stability, rigidity of structure, etc. [32].

\subsubsection{UV-Vis Spectroscopic Analysis}

The UV-Vis spectral analysis was measured using Shimadzu UV-2400 PC series spectrophotometer over a wavelength range of 200-400 $\mathrm{nm}$ with $1 \mathrm{~cm}$ quartz cell and a slit width of $2.0 \mathrm{~nm}$. This analysis was performed to evaluate the effect of biofield treatment on the structural property of 2-ClBN sample. The UV-Vis spectroscopy gives the preliminary information related to the skeleton of chemical structure and possible arrangement of functional groups. With UV-Vis spectroscopy, it is possible to investigate electron transfers between orbitals or bands of atoms, ions and molecules existing in the gaseous, liquid and solid phase [32].

\section{Results and Discussion}

\subsection{X-ray Diffraction}
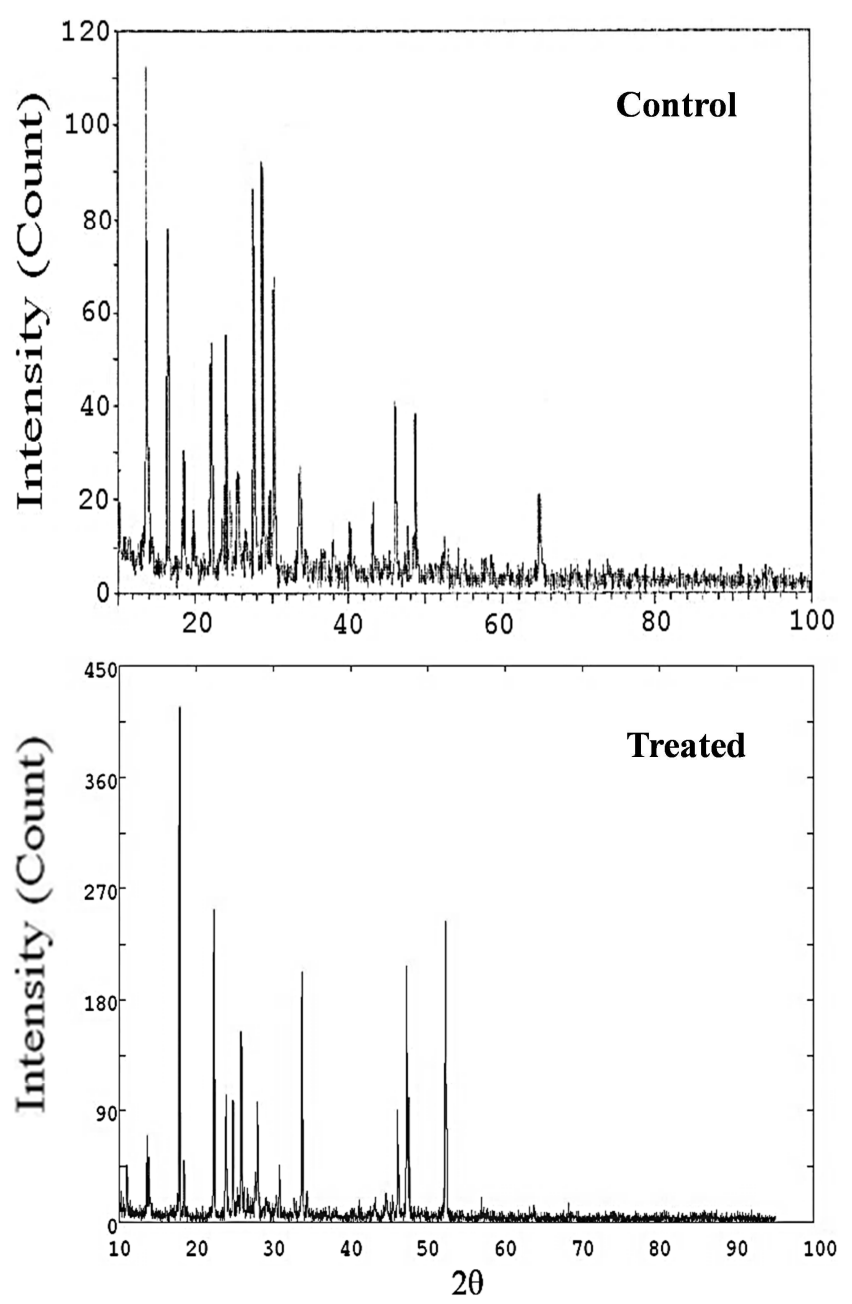

Fig. 1. XRD diffractogram of control and treated samples of 2-chlorobenzonitrile.

X-ray diffraction analysis was conducted to study the crystalline nature of the control and treated sample of 2-ClBN. XRD diffractogram of control and treated samples of 2-ClBN are shown in Fig. 1. The XRD diffractogram of control 2-ClBN showed intense crystalline peaks at $2 \theta$ equals to $13.67^{\circ}, 16.62^{\circ}, 27.74^{\circ}, 28.87^{\circ}$ and $30.28^{\circ}$. The intense peaks indicated the crystalline nature of $2-\mathrm{ClBN}$. However, the XRD diffractogram of treated 2-ClBN showed the crystalline peak at $2 \theta$ equals to $13.59^{\circ}, 17.82^{\circ}, 22.28^{\circ}$, $23.84^{\circ}, 24.77^{\circ}, 25.80^{\circ}, 27.91^{\circ}$, and $33.65^{\circ}$. Most of the treated sample peaks showed high intensity as compared to the control, which indicated that crystallinity of treated 2-ClBN sample increased as compared to control. According to Britton $\mathrm{D}, 2-\mathrm{ClBN}$ molecules involve $\mathrm{Cl}---\mathrm{N}$ interactions as well as $\mathrm{C}-\mathrm{H}---\mathrm{Cl}$ and $\mathrm{C}-\mathrm{H}---\mathrm{N}$ hydrogen bonds, due to which they possess four crystallographic non-equivalent forms of molecules. These four crystallographic molecules differed from each other in terms of bond length and related by pseudosymmetry [33]. Besides, the molecules of 2-ClBN do not possess an organized structure as the molecular layers 
are not perfectly overlapping with each other [34]. It is presumed that biofield energy may be absorbed by the treated 2-ClBN molecules that may lead to increasing the symmetry of 2-ClBN molecules by formation of a symmetrical crystalline long range pattern. Further, the molecular layers of 2-ClBN get more organized after biofield treatment hence, caused an increase in the intensity of peaks. Besides, the crystallite size was found to be 99.72 and 94.85 $\mathrm{nm}$ in control and treated 2-ClBN, respectively. The crystallite size was decreased by $4.88 \%$ in treated $2-\mathrm{ClBN}$ as compared to control (Fig. 2). It may be due to biofield energy that probably induce strain in the lattice, and that possibly resulted in the fracturing of grains into subgrains and hence decreased crystallite size [29]. 2-ClBN is used as intermediate in the synthesis of many pharmaceutical compounds; hence, the decrease in crystallite size may lead to fasten the rate kinetics that ultimately enhances the percentage yield of end products [35].

\subsection{Surface Area Analysis}

The surface area of control and treated samples of 2-ClBN were investigated using BET method. The control sample showed a surface area of $0.764 \mathrm{~m}^{2} / \mathrm{g}$; however, the treated sample of 2-ClBN showed a surface area of $0.271 \mathrm{~m}^{2} / \mathrm{g}$. The decrease in surface area was $64.53 \%$ in the treated 2-ClBN sample as compared to control (Fig. 2). Murray et al. reported that increase in crystallinity might reduce the surface area as poorly crystallized sample possess more surface area than a well-crystallized sample [36]. As it was evident from XRD studies that after biofield treatment, the crystallinity of 2-ClBN sample increases, hence it could lead to decrease the surface area of treated sample as compared to control.

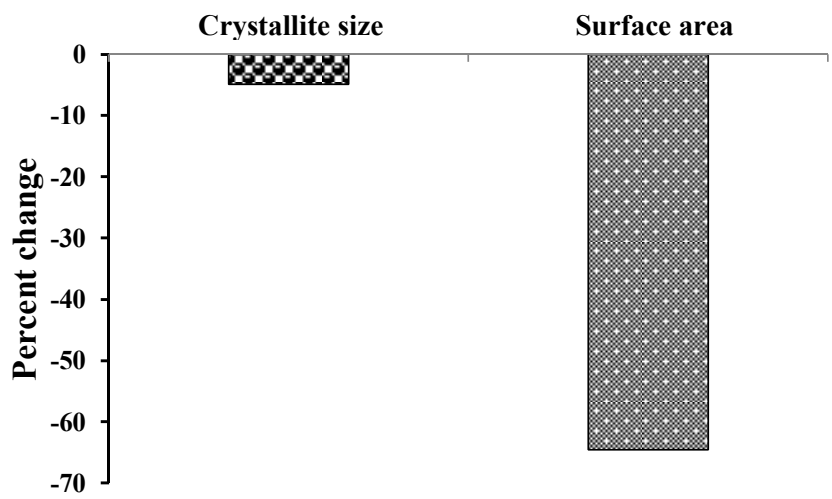

Fig. 2. Percent change in crystallite size and surface area of treated sample of 2-chlorobenzonitrile.

\subsection{DSC Analysis}

DSC was used to determine the latent heat of fusion $(\Delta \mathrm{H})$ and melting temperature in control and treated sample of 2-ClBN. The DSC analysis results of control and treated samples of 2-ClBN are presented in Table 1. In a solid, the amount of energy required to change the phase from solid to liquid is known as $\Delta \mathrm{H}$. The data showed that $\Delta \mathrm{H}$ was increased from $96.22 \mathrm{~J} / \mathrm{g}$ (control) to $123.87 \mathrm{~J} / \mathrm{g}$ in treated 2 -ClBN. It indicates that $\Delta \mathrm{H}$ was increased by $28.74 \%$ in treated sample as compared to control (Fig. 3). It was previously reported that $2-\mathrm{ClBN}$ molecules possess $\mathrm{CN}---\mathrm{Cl}$ intermolecular interactions but these interactions are weak in nature due to which 2-ClBN molecules possess lower enthalpy of sublimation as compared to other isomers [34]. It was hypothesized that biofield energy was absorbed by 2-CIBN molecules that possibly strengthened the intermolecular bonding between chlorine-cyano groups in 2-ClBN molecules. Hence, the treated 2-ClBN sample needs more energy in the form of $\Delta \mathrm{H}$ to undergo the process of melting. Moreover, the melting temperature of treated 2-ClBN was increased from $45.78^{\circ} \mathrm{C}$ (control) to $46.72^{\circ} \mathrm{C}$. Thus, data suggest that melting point was increased by $2.05 \%$ as compared to control (Fig. 3). The melting temperature is related to the kinetic energy of the atoms [37]. Previously, our group reported that biofield treatment has altered $\Delta \mathrm{H}$ and melting point in lead and tin powder [38]. Besides, the increase of melting point in treated 2-ClBN suggests that kinetic energy and thermal vibrations of molecules probably altered after biofield treatment.

\subsection{TGA/DTG Analysis}

Thermogravimetric analysis/derivative thermogravimetry analysis (TGA/DTG) of control and biofield treated samples are summarized in Table 1. TGA thermogram (Fig. 4) showed that control 2-ClBN sample started losing weight around $132^{\circ} \mathrm{C}$ (onset) and stopped around $178^{\circ} \mathrm{C}$ (end set). However, the treated 2-ClBN started losing weight around $139^{\circ} \mathrm{C}$ (onset) and terminated around $176^{\circ} \mathrm{C}$ (end set). It indicates that onset temperature of treated 2-ClBN increased by $5.3 \%$ as compared to control (Fig. 3). Furthermore, in this process, control sample lost $61.05 \%$ and treated 2-CIBN sample lost $46.15 \%$ of its weight. Besides, DTG thermogram data showed $\mathrm{T}_{\max }$ at $150.65^{\circ} \mathrm{C}$ in control, whereas, it was increased to $155.52^{\circ} \mathrm{C}$ in treated $2-\mathrm{ClBN}$ (Table 1). It indicates that $\mathrm{T}_{\max }$ was increased by $3.23 \%$ in treated 2-ClBN (Fig. 3). The increase in onset temperature can be related to increasing in thermal stability of treated 2-ClBN sample. As it was interpreted from DSC studies that $\Delta \mathrm{H}$ increased by $28.74 \%$ which suggest that intermolecular bonding between $\mathrm{Cl}---\mathrm{CN}$ group might strengthen after biofield treatment ultimately results to improve the stability of treated 2-ClBN sample against temperature. Furthermore, this hypothesis was also supported by the percent weight loss that is decreased by $15 \%$ in treated sample as compared to control. The result was also evident by $\mathrm{T}_{\max }$ value that was increased by $3.23 \%$ in treated sample; hence suggest that the temperature at which maximum weight loss occurred was increased by $5^{\circ} \mathrm{C}$ in treated sample as compared to control.

The overall thermal studies suggest that thermal stability of treated 2-ClBN sample increased which might be advantageous for this compound regarding its wide application. 


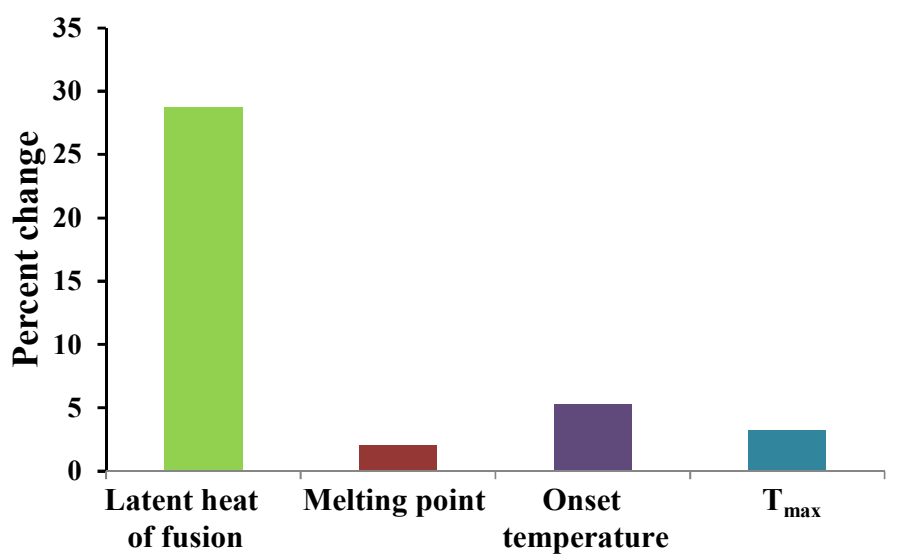

Fig. 3. Percent change in latent heat of fusion, melting point, onset temperature and $T_{\max }$ in biofield treated 2-chlorobenzonitrile with respect to control.
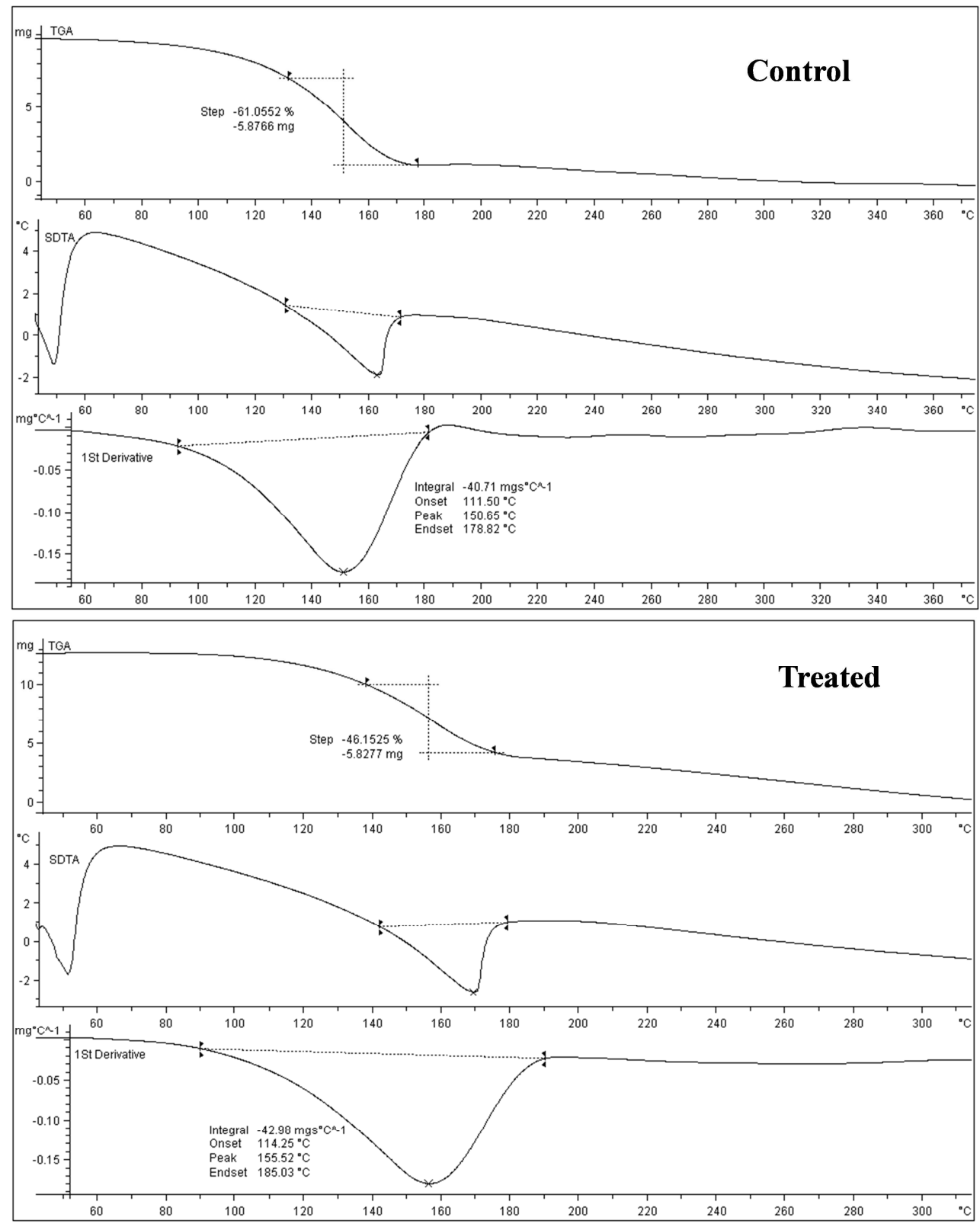

Fig. 4. TGA thermograms of control and treated samples of 2-chlorobenzonitrile. 
Table 1. Thermal analysis of control and treated samples of 2-chlorobenzonitrile.

\begin{tabular}{lll}
\hline Parameter & Control & Treated \\
\hline Latent heat of fusion $\Delta \mathrm{H}(\mathrm{J} / \mathrm{g})$ & 96.22 & 123.87 \\
Melting point $\left({ }^{\circ} \mathrm{C}\right)$ & 45.78 & 46.72 \\
Onset temperature $\left({ }^{\circ} \mathrm{C}\right)$ & 132 & 139 \\
$\mathrm{~T}_{\max }\left({ }^{\circ} \mathrm{C}\right)$ & 150.65 & 155.52 \\
Weight loss $(\%)$ & 61.05 & 46.15 \\
\hline
\end{tabular}

$\mathrm{T}_{\max }$ : temperature at which maximum weight loss occur

\subsection{Spectroscopic Studies}

\subsubsection{FT-IR Analysis}

FT-IR spectra of control, T1 and T2 samples of 2-ClBN are shown in Fig. 5. It showed similar distribution patterns for both control and treated (T1 and T2) samples of 2-ClBN. The C-H stretching (aromatic) peak was appeared at $3066 \mathrm{~cm}^{-1}$ in control 2-ClBN. In treated samples, C-H stretching (aromatic) peak was appeared at same frequency i.e. $3066 \mathrm{~cm}^{-1}$ in $\mathrm{T} 1$ and $\mathrm{T} 2$ sample. The peak due to overtone (in ring) was appeared at 2341, 2339 and $2341 \mathrm{~cm}^{-1}$ in control, T1 and T2 sample respectively. The $\mathrm{C} \equiv \mathrm{N}$ stretching peak was appeared at $2229 \mathrm{~cm}^{-1}$ in control and $\mathrm{T} 1$ and $2231 \mathrm{~cm}^{-1}$ in $\mathrm{T} 2$ sample. The peak due to $\mathrm{C}-\mathrm{C}$ stretching (in ring) was appeared at $1591 \mathrm{~cm}^{-1}$ in all three samples i.e. control, T1 and T2. Similarly, C-H in plane bending was found at 1134 $\mathrm{cm}^{-1}$ in all three samples i.e. control, T1 and T2. The peaks due to $\mathrm{C}-\mathrm{Cl}$ stretching were also appeared at same frequencies in control and treated (T1 and T2) samples i.e. at 557 and $459 \mathrm{~cm}^{-1}$. The peak due to C-H out of plane bending was appeared at $759 \mathrm{~cm}^{-1}$ in control and T1 sample whereas, at $758 \mathrm{~cm}^{-1}$ in T2 sample. $\mathrm{C}-\mathrm{C} \equiv \mathrm{N}$ stretching peak was appeared at $1203 \mathrm{~cm}^{-1}$ in all three samples i.e. control, $\mathrm{T} 1$ and $\mathrm{T} 2$. The peak due to $\mathrm{C}-\mathrm{Cl}$ in plane bending was found at $386 \mathrm{~cm}^{-1}$ in control whereas, at $370 \mathrm{~cm}^{-1}$ in $\mathrm{T} 1$ and $385 \mathrm{~cm}^{-1}$ in T2 sample of 2-CIBN. The FT-IR spectra were well supported by reference data [39].

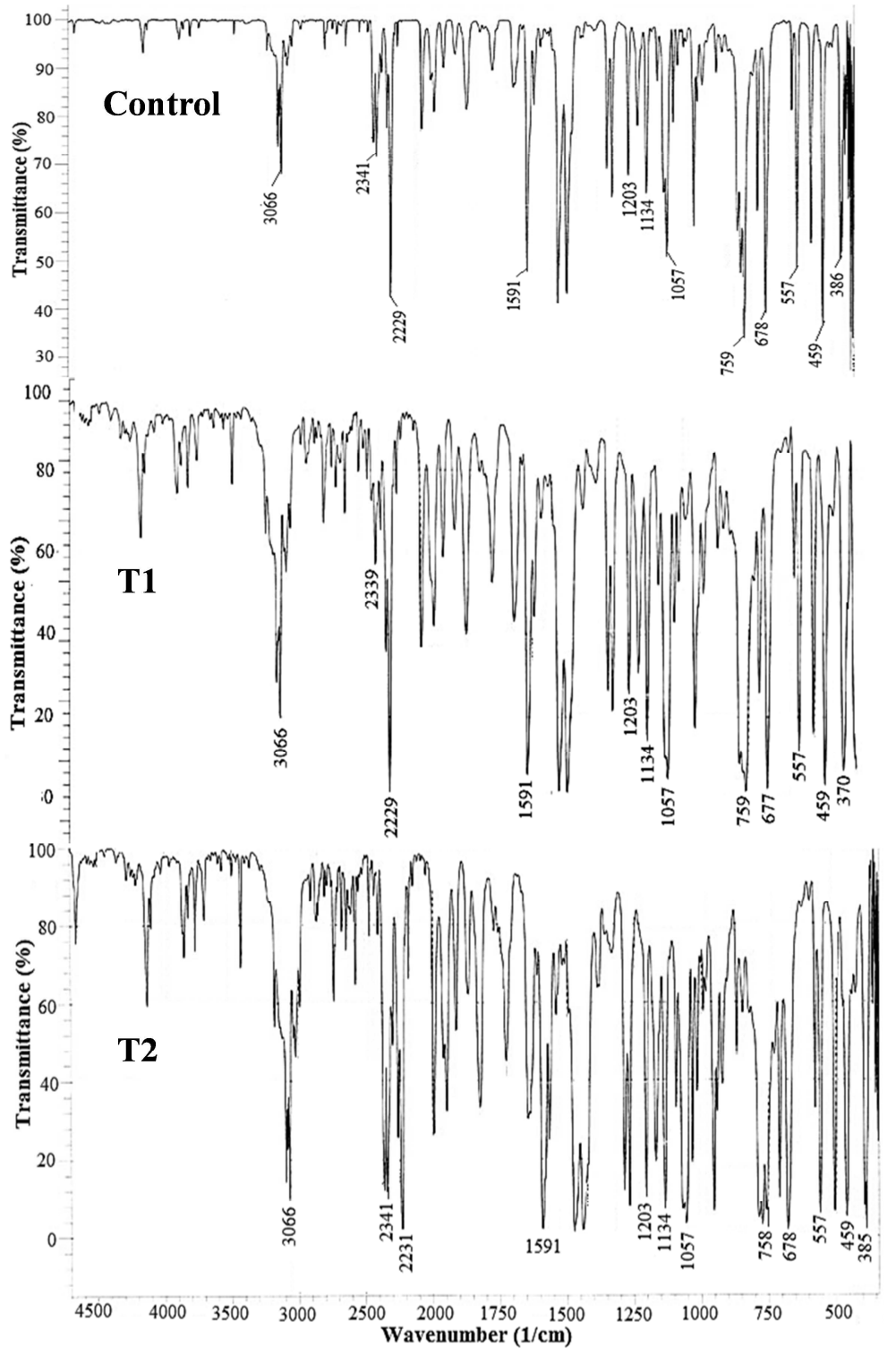

Fig. 5. FT-IR spectra of control and treated samples of 2-chlorobenzonitrile. 
The FT-IR spectroscopic study showed that no alteration was found in FT-IR spectra of treated samples (T1 and T2) as compared to control. It suggests that biofield treatment did not cause any alteration in structural and bonding properties like bond strength, stability, the rigidity of structure, etc.

\subsubsection{UV-Vis Spectroscopic Analysis}

The UV spectra of control and treated samples (T1 and T2) of 2-CIBN are shown in Fig. 6. The UV spectrum of control sample showed characteristic absorption peaks at 206 and 229 $\mathrm{nm}$ which were also observed in T1 sample at 209 and $229 \mathrm{~nm}$; however, in case of T2 sample, the peak near to $210 \mathrm{~nm}$ get merged with the next peak due to increase in intensity and form one broad peak at $228 \mathrm{~nm}$. Also, the peak at $229 \mathrm{~nm}$ in

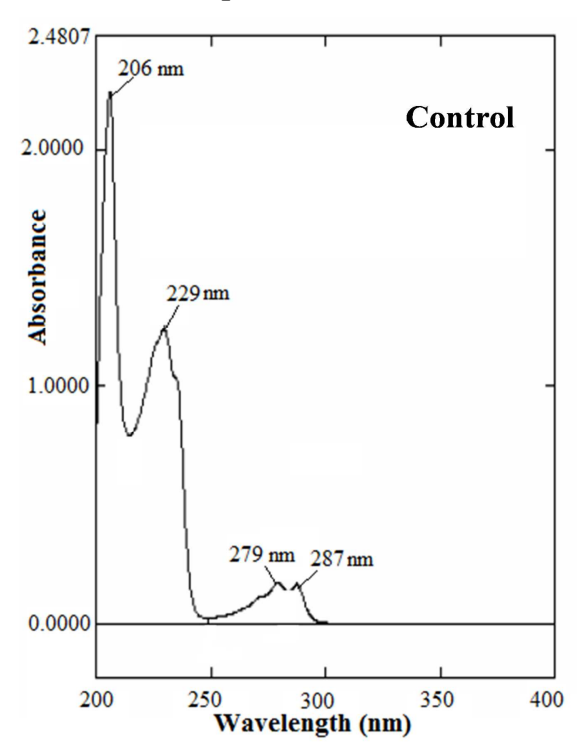

T1 sample showed increase intensity as compared to control. Other two absorption peaks were observed at 279 and $287 \mathrm{~nm}$ in the control sample that were evident in T1 and T2 at the same position however some change in intensity was observed in T2 sample as compared to control. It was reported previously that intensity of peak might increase due to intermolecular bonding between molecules of the sample [40]. Hence, it is hypothesized that due to biofield treatment, the strength and extent of intermolecular bonding between $\mathrm{CN}---\mathrm{Cl}$ group increased, which results in increased intensity of peaks in treated samples as compared to control. The UV spectrum of control 2-ClBN was well supported by literature data [39].

Fig. 6. UV-Vis spectra of control and treated samples of 2-chlorobenzonitrile.

\section{Conclusions}

The overall study showed the influence of biofield treatment on physical, thermal and spectroscopic properties of 2-ClBN. XRD results showed that crystallite size was decreased by $4.88 \%$ in treated 2-ClBN samples as compared to control, which might be due to fracturing of grains into subgrains caused by lattice strain produced via biofield energy. The increase in the intensity of peaks suggests the increased crystallinity of treated sample due to the formation of symmetrical and organised molecular layers caused via biofield treatment. The reduced crystallite size and increased crystallinity may lead to increasing the reaction kinetics as well as the stability of 2-ClBN, which could make it more useful as an intermediate compound. The surface area analysis showed $64.53 \%$ decrease in surface area of the treated 2-ClBN sample as compared to the control that might result due to increase in crystallinity and formation of a well-crystallised sample after biofield treatment. DSC analysis data revealed that latent heat of fusion as well as melting temperature were increased by $28.74 \%$ and $2.05 \%$ respectively in treated 2-ClBN as compared to control. TGA/DTG studies showed that onset temperature and $\mathrm{T}_{\max }$ were increased by $5.3 \%$ and $3.23 \%$ respectively in treated $2-\mathrm{ClBN}$ samples. On the basis of thermal analysis data, it is hypothesized that thermal stability of treated 2-ClBN sample increased which may affect its shelf life and efficacy when used in various chemical reactions. The UV-Vis spectra showed alteration in the intensity of peaks that might happen due to increase in intermolecular bonding in 2-ClBN molecules after biofield treatment. This increase in intermolecular bonding can further relate to increased thermal stability of treated sample as compared to control. Therefore, it is assumed that biofield treated 2-ClBN could be more useful in the production of various pharmaceutical products.

\section{Acknowledgements}

The authors would like to acknowledge the whole team of Sophisticated Analytical Instrument Facility (SAIF), Nagpur, Indian Rubber Manufacturers Research Association (IRMRA), Thane and MGV Pharmacy College, Nashik for providing the instrumental facility. Authors greatly acknowledge the support of Trivedi Science, Trivedi Master Wellness and Trivedi Testimonials in this research work. 


\section{References}

[1] Maki T, Takeda K (2002) Benzoic acid and derivatives. Ullmann's Encyclopedia of Industrial Chemistry, Wiley-VCH, Weinheim.

[2] Schareina T, Zapf A, Beller M (2004) Improving palladium-catalyzed cyanation of aryl halides: development of a state-of-the-art methodology using potassium hexacyanoferrate (II) as cyanating agent. J Organomet Chem 689: 4576-4583.

[3] Kumar V, Panikar Y, Palafox MA, Vats JK, Kostova I, et al. (2010) Ab-initio calculations, FT-IR and FT-Raman spectra of 2-chloro-6-methyl benzonitrile. Indian J Pure Ap Phy 48: 85-94.

[4] Schormann N, Velu SE, Murugesan S, Senkovich O, Walker K, et al. (2010) Synthesis and characterization of potent inhibitors of trypanosoma cruzi dihydrofolate reductase. Bioorg Med Chem 18: 4056-4066.

[5] Estrada AA, Liu X, Baker-Glenn C, Beresford A, Burdick DJ, et al. (2012) Discovery of highly potent, selective, and brain-penetrable leucine-rich repeat kinase 2 (LRRK2) small molecule inhibitors. J Med Chem 55: 9416-9433.

[6] Doucet-Personeni C, Bentley PD, Fletcher RJ, Kinkaid A, Kryger G, et al. (2001) A structure-based design approach to the development of novel, reversible AChE inhibitors. J Med Chem 44: 3203-3215.

[7] Barta TE, Veal JM, Rice JW, Partridge JM, Fadden RP, et al (2008) Discovery of benzamide tetrahydro-4H-carbazol-4-ones as novel small molecule inhibitors of $H_{s p} 90$. Bioorg Med Chem Lett 18: 3517-3521.

[8] Sweeney ZK, Harris SF, Arora SF, Javanbakht H, Li Y, et al (2008) Design of annulated pyrazoles as inhibitors of HIV-1 reverse transcriptase. J Med Chem 51: 7449-7458.

[9] Ozdemir I, Gurbuz N, Kaloglu N, Dogan O, Kaloglu M, et al. (2013) N-Heterocyclic carbene-palladium catalysts for the direct arylation of pyrrole derivatives with aryl chlorides. Beilstein J Org Chem 9: 303-312.

[10] Heilman WP, Battershell RD, Pyne WJ, Goble PH, Magee TA (1978) Synthesis and antiinflammatory evaluation of substituted isophthalonitriles, trimesonitriles, benzonitriles, and terephthalonitriles. J Med Chem 21: 906-913.

[11] Blessy M, Patel RD, Prajapati PN, Agrawal YK (2014) Development of forced degradation and stability indicating studies of drugs-A review. J Pharm Anal 4: 159-165.

[12] Panyachariwat N, Steckel H (2014) Stability of urea in solution and pharmaceutical preparations. J Cosmet Sci 65: 187-195.

[13] Planck M (1903) Treatise on thermodynamics. (3rdedn), english translated by Alexander OGG, Longmans, Green, London (UK).

[14] Einstein A (1905) Does the inertia of a body depend upon its energy-content? Ann Phys 18: 639-641.

[15] Rivera-Ruiz M, Cajavilca C, Varon J (2008) Einthoven's string galvanometer: The first electrocardiograph. Tex Heart Inst J 35: 174-178.

[16] Rubik B (2002) The biofield hypothesis: Its biophysical basis and role in medicine. J Altern Complement Med 8: 703-717.
[17] Garland SN, Valentine D, Desai K, Langer C, Evans T, et al. (2013) Complementary and alternative medicine use and benefit finding among cancer patients. J Altern Complement Med 19: 876-881.

[18] Giasson M, Bouchard L (1998) Effect of therapeutic touch on the well-being of persons with terminal cancer. J Holist Nurs 16: 383-398.

[19] Peck SD (1998) The efficacy of therapeutic touch for improving functional ability in elders with degenerative arthritis. Nurs Sci Q 11: 123-132.

[20] Turner JG, Clark AJ, Gauthier DK, Williams M (1998) The effect of therapeutic touch on pain and anxiety in burn patients. J Adv Nurs 28: 10-20.

[21] Trivedi MK, Bhardwaj Y, Patil S, Shettigar H, Bulbule, A (2009) Impact of an external energy on Enterococcus faecalis [ATCC-51299] in relation to antibiotic susceptibility and biochemical reactions-an experimental study. J Accord Integr Med 5: 119-130.

[22] Trivedi MK, Patil S (2008) Impact of an external energy on Staphylococcus epidermis [ATCC-13518] in relation to antibiotic susceptibility and biochemical reactions-an experimental study. J Accord Integr Med 4: 230-235.

[23] Trivedi MK, Patil S (2008) Impact of an external energy on Yersinia enterocolitica [ATCC-23715] in relation to antibiotic susceptibility and biochemical reactions: An experimental study. Internet J Alternat Med 6: 13.

[24] Shinde V, Sances F, Patil S, Spence A (2012) Impact of biofield treatment on growth and yield of lettuce and tomato. Aust $\mathrm{J}$ Basic Appl Sci 6: 100-105.

[25] Sances F, Flora E, Patil S, Spence A, Shinde V (2013) Impact of biofield treatment on ginseng and organic blueberry yield. Agrivita J Agric Sci 35: 22-29.

[26] Lenssen AW (2013) Biofield and fungicide seed treatment influences on soybean productivity, seed quality and weed community. Agricultural Journal 8: 138-143.

[27] Nayak G, Altekar N (2015) Effect of biofield treatment on plant growth and adaptation. J Environ Health Sci 1: 1-9.

[28] Patil SA, Nayak GB, Barve SS, Tembe RP, Khan RR (2012) Impact of biofield treatment on growth and anatomical characteristics of Pogostemon cablin (Benth.). Biotechnology 11: $154-162$.

[29] Trivedi MK, Tallapragada RR (2008) A transcendental to changing metal powder characteristics. Met Powder Rep 63: 22-28.

[30] Dabhade VV, Tallapragada RR, Trivedi MK (2009) Effect of external energy on atomic, crystalline and powder characteristics of antimony and bismuth powders. Bull Mater Sci 32: 471-479.

[31] Trivedi MK, Nayak G, Patil S, Tallapragada RM, Latiyal O (2015) Studies of the atomic and crystalline characteristics of ceramic oxide nano powders after bio field treatment. Ind Eng Manage 4: 161 .

[32] Pavia DL, Lampman GM, Kriz GS (2001) Introduction to spectroscopy. (3rdedn), Thomson Learning, Singapore.

[33] Britton D (2007) o-Chloro- and o-bromobenzo-nitrile: Pseudosymmetry and pseudo-isostructural packing. Acta Crystallogr C 63: o14-o16. 
[34] Rocha IM, Galvao TLP, Ribeiro da Silva MDMC, Ribeiro da Silva MAV (2014) Thermodynamic study of chlorobenzonitrile isomers: A survey on the polymorphism, pseudosymmetry, and the chloro $\cdots$ cyano interaction. J Phys Chem 118: 1502-1510.

[35] Chaudhary AL, Sheppard DA, Paskevicius M, Pistidda C, Dornheim M, et al. (2015) Reaction kinetic behaviour with relation to crystallite/grain size dependency in the $\mathrm{Mg}-\mathrm{Si}-\mathrm{H}$ system. Acta Mater 95: 244-253.

[36] Murray HH, Lyons SC (1960) Further correlation of kaolinite crystallinity with chemical and physical properties. Clays Clay Miner 8: 11-17.

[37] Moore J (2010) Chemistry: The molecular science. (4thedn), Brooks Cole, Belmont, U.S.
[38] Trivedi MK, Patil S, Tallapragada RM (2013) Effect of biofield treatment on the physical and thermal characteristics of silicon, tin and lead powders. J Material Sci Eng 2: 125.

[39] Krishnan AR, Saleem H, Subashchandrabose S, Sundaraganesan N, Sebastain S (2011) Molecular structure, vibrational spectroscopic (FT-IR, FT-Raman), UV and NBO analysis of 2-chlorobenzonitrile by density functional method. Spectrochim Acta A Mol Biomol Spectrosc 78: 582-589.

[40] Forbes WF, Templeton JF (1958) The study of hydrogen bonding and related phenomena by ultraviolet light absorption. Can J Chem 36: 180-188. 